\title{
Determinant Factors of Neonatal Near Miss Among Neonates in Gurage Zone Hospitals, Ethiopia: A Case-Control Study
}

This article was published in the following Dove Press journal: Pediatric Health, Medicine and Therapeutics

\author{
Haimanot Abebe (D)' \\ Abebaw Wasie' \\ Alex Yeshaneh iD $^{2}$ \\ Solomon Shitu ${ }^{2}$ \\ Ayenew Mose (iD) ${ }^{2}$ \\ Daniel Adane ${ }^{2}$ \\ Haile Workye (iD ${ }^{3}$ \\ Molla Gashu (D)
}

'Department of Public Health, College of Medicine and Health Sciences, Wolkite University, Wolkite, Ethiopia; ${ }^{2}$ Department of Midwifery, College of Medicine and Health Sciences, Wolkite University, Wolkite, Ethiopia; ${ }^{3}$ Department of Nursing, College of Medicine and Health Sciences, Wolkite University, Wolkite, Ethiopia
Correspondence: Haimanot Abebe Department of Public Health, College of Medicine and Health Sciences, Wolkite University, P.O.Box: 07, Wolkite, Ethiopia Tel +251921288680

Email haimanotabebe78@gmail.com
Introduction: It is highly economical and commendable to identify the determinants of neonatal near miss which will be utilized as proxy determinants of neonatal mortality rate. However, neither determinants of neonatal mortality rate nor a determinant of a neonatal near miss are adequately investigated specifically within the study area. Therefore, this study is aimed to identify the determinants of neonatal near-miss among neonates admitted in hospitals of the Gurage zone, Southern Ethiopia.

Methods and Materials: Unmatched case-control study was conducted to identify factors associated with neonatal near-miss among neonates admitted in Gurage zone hospitals. A pre-tested structured interviewer-administered questionnaire was used to collect the data. Besides, data related to the clinical diagnosis of neonates and managements given were extracted from patient records. In this study, a total of 105 cases and 209 controls have participated. To recruit cases and controls consecutive sampling methods and simple random sampling techniques were used respectively. Data were entered using Epi Data software and exported to SPPS for analysis. To identify the determinate factors of the outcome variable binary and multivariable logistic regression were employed.

Results: The determinate factors of the outcome variable include a history of abortion with AOR 3.9 [95\%C1 3.53-10.15], referred from other health care institution AOR 7.53[95\% CI 3.99-14.22], severe maternal morbidity during pregnancy AOR 4.57[95\% CI 1.77-11.79], cesarean section mode of delivery 4.45[95\% CI 1.76-11.25], and good essential newborn care knowledge AOR 3.33[95\% CI 1.54-7.19].

Conclusion: In this study, easily modifiable/preventable maternal and health service utilization-related factors are increasing the menace of a neonatal near-miss in the Gurage zone. It is the signal that shows the primary health care program needs to be further enhanced to bring more desirable health outcomes and/or effectiveness of health policies needs to be examined to introduce more impactful strategies.

Keywords: determinants, neonatal near miss, severe neonatal morbidity, Ethiopia

\section{Introduction}

The period starting from the first 28 days of life to birth is called a neonatal period. In this period dying is highest with an average rate of 18 deaths per 1,000 live births globally in 2018. ${ }^{1}$ Preventable causes such as prematurity, complications around the time of birth, infections, and congenital conditions contribute to greater than 2.5 million deaths of neonates, which consist of $44 \%$ of under-five mortality in $2017 .{ }^{2,3}$ Low- and middle-income countries account for huge newborn deaths as 
compared with a developed country. Sub-Saharan African countries including Ethiopia and other developing nations have constituent two-thirds of all neonatal mortality. ${ }^{4}$

An infant who nearly died but keeps up with a severe complication that happened during the perinatal period is defined as a neonatal near miss. Pragmatic and management markers of severe neonatal morbidity criteria are used for measuring the case. The use of this combined criteria revealed a very good performance as a factor of early neonatal mortality. Pragmatic criteria used for measuring NNM case is a reason for most deaths of the neonate in the globe. ${ }^{5,6}$

Globally, preterm-related complications contributed to $35 \%$ of deaths, and birth asphyxia attributed to $24 \%$ of neonatal mortality. ${ }^{7}$ Similarly, $14 \%$ of newborns delivered globally were LBW with the highest in Asian and African countries. ${ }^{8,9}$ These conditions affect childhood growth and development and also have a link with the chronic medical disease. ${ }^{10,11}$ Finally, this yields mental, clubby, and economical problems for the family, and the community. ${ }^{12}$

The magnitude of NNM widely varies across studies because of the difference in criteria used. ${ }^{13-18}$ As studies that used only pragmatic criteria, the incidence of NNM varied between 21.4-86.7 per 1000 live births in Brazil and India respectively. ${ }^{5,19}$ Whereas, according to those studies that used pragmatic and management criteria, the incidence of NNM ranged between 39.2-367 per 1000 live births. ${ }^{16,20}$

The most common causes of neonatal mortality are primary maternal causes like spontaneous preterm birth, infections, hypertension, antepartum hemorrhage, preexisting maternal disease are known to have adverse neonatal outcomes. ${ }^{21}$ An adverse birth outcome has an impact on early childhood wellbeing and development including behavioral problems, education capability, medical disease, and increased risk of dependency. ${ }^{11}$ The sociodemographic factors, maternal and obstetric factors (maternal near-miss, null parity, previous $\mathrm{c} / \mathrm{s}$, APH, and vaginal mode of delivery) have an association with a neonatal near miss. ${ }^{6,16,22-26}$

As the under-five death rate dropped to 43 per 1000 in 2015 from 91 deaths per 1000 live births since the 1990s remarkable progression has been done for enhancing childhood survival. Twelve developing countries including Ethiopia had downscale the under-five death rate by $2 / 3$ and above. ${ }^{27}$ The decreasing trend of the neonatal mortality rate was not as great as childhood reproductive health indicators in Ethiopia. According to 2011, 2016, and 2019
Ethiopia central statically Agency (CSA) report 31, 29, and 30 neonatal deaths had occurred per 1000 live births respectively, which illustrate a sluggish decline during the respective aforementioned years. ${ }^{28-30}$

Decreasing neonatal death is one of the continuum development pillars endorsed by global countries to downscale neonatal mortality below 12 per 1000 for all countries by $2030 .^{31}$ Despite the pooled death of under-five reduction across various global countries, the pattern of reduction is not similar even across ecological child age groups and low-income countries where neonates are dying more than other cohorts. ${ }^{32}$ With the current trend of neonatal mortality rate, Ethiopia could not achieve the SDG target of neonatal mortality rate target set by 2030 $\mathrm{GC}^{33}$

Therefore, identifying the factors associated with a neonatal near miss is the first step in designing a technique to drop neonatal death and its consequences. Besides, it is highly economical and commendable to associate the determinant factors of neonatal near misses that can be utilized as proxy determinants of neonatal death. However, the determinant factors of a neonatal near miss are not adequately investigated specifically in the study area. Besides, the inconsistent findings of the determinate factors of a neonatal near miss, and the methodological limitation on measuring the outcome variable in previously published works are some of the gaps. So then, this study was imagined to fill the forenamed gaps. Therefore, this study is aimed to identify the determinant factors of neonatal near-miss among neonates admitted in Gurage zone hospitals, Southern Ethiopia.

\section{Methods and Materials}

\section{Study Area}

The southern region of Ethiopia has included the Gurage zone as one of the administrative zones in the region. The zone constituent's fifteen districts and four town administrations. The capital town of the zone is Wolkite town which is found $153 \mathrm{~km}$ away from Addis Ababa, the capital city of Ethiopia. The Gurage zone has a total population of $1,279,646$, of which 657,568 are women, Based on the 2007 population census in the country. ${ }^{34}$ In the zone, seven hospitals providing population (five governments and two private). Comprehensive emergency obstetric care services are given by all hospitals in the zone. Besides, basic emergency obstetric care services are delivered by all 72 health centers in the zone. In this 
study, all hospitals which are found in the zone were enlisted in the study.

\section{Study Period}

The study was conducted among neonates admitted to seven hospitals in the Gurage zone, Southwest Ethiopia, from November 2019 to February 2020.

\section{Study Design}

An unmatched case-control analysis was performed among neonates admitted in Gurage zone hospitals, Southwest Ethiopia.

\section{Study Population}

The study populations were neonates who were admitted to obstetrics and pediatrics wards in Gurage zone hospitals throughout the study period.

\section{Cases}

Neonates with one of the following features (birth weight less than $1.7 \mathrm{~kg}$, APGAR score less than 7 , gestational age less than 33 weeks and/or parenteral antibiotic treatment, nasal CPAP (Continuous supportive airway pressure), any intubation during the first week of life, phototherapy within 24 hours of birth, cardiopulmonary resuscitation, vasoactive drug use, anticonvulsants use, surfactant use, blood product use, steroid use, surgery during the first week of birth). ${ }^{5}$

\section{Control}

Neonates that were admitted because of non-near-miss neonatal conditions and neonates brought for postnatal care treatment.

\section{Eligibility Criteria} Inclusion Criteria

This study included neonates who were taken to hospitals in the Gurage zone for treatment or postnatal care during the study period.

\section{Exclusion Criteria}

Those neonates whose mothers died and twin neonates were excluded from this study. Those newborns selected as control but suddenly returned as a case during the study period were also omitted from the control without substitution but they were employed as a neonatal near-miss case. Those neonates who did not accompany by their mothers were also excluded from this study.

\section{Sample Size Determination}

Epi Info 7 tool was used to calculate the sample size. To calculate the sample size the assumption of $95 \%$ confidence level, $80 \%$ power, 1:2 case-control ratio, and expected percent of near-miss among women with no hemorrhage is taken $16.2 \%$ with an odds ratio of 2.2 compared to women with hemorrhage. ${ }^{23}$ Accordingly, the analysis contained 105 cases and 209 controls.

\section{Sampling Technique and Procedure}

To recruit the study subject, a consecutive and a simple random sampling technique was for cases and controls respectively. Hospital admission logbooks, operation theatre logbooks, and patient cards by pediatric nurses were used to identify cases, and then senior pediatricians working in the corresponding hospitals have approved the cases. For each approved near-miss case, two controls were picked using a simple random sampling technique. Identification of cases and controls was made after neonates are stabilized from their clinical condition and ready for discharge from hospitals.

\section{Data Collection Tools and Procedures}

The Unmet Obstetric Need project led by the Institute of Tropical Medicine in Antwerp and the World Health Organization Multi-Country Survey Project on severe maternal morbidity, ${ }^{5,7}$ which is refined for neonatal near miss research, the data was collected. A slight change was made to the local context. The questionnaire includes socioeconomic variables, maternal and child healthrelated variables, knowledge-related variables, and neonatal danger sign variables. The events of neonatal near misses were defined based on the above criteria by pediatric nurses in obstetrics and pediatrics wards. A pre-tested, structured interviewer-administered questioner was used to collect the data. The mothers of the children chosen were interviewed. Data that cannot be accessed by questioning mothers, such as diagnosis and management given was obtained from patient records. In the data collection activity, twenty-one midwives and pediatric nurses were involved. In the data collection period, seven field supervisors were involved.

Before they gave consent to participate, mothers were informed about all the details of the study. The women were encouraged to feel free and were assured that their answers were confidential and that no information, except for the researcher, was shared with third parties. After this, 
in a quiet and ample room, women who were willing to integrate and sign the informed consent document were interviewed. Questionnaires or data obtained by the supervisor have been examined and cross-checked for completeness, accuracy, and quality, and the main investigator had also taken corrective measures to enhance the validity of the finding.

\section{Operational Definitions}

Neonatal near miss: Neonatal near-miss was assessed when at least one of the following suggested criteria was outfaced by the newborn but survived those complications. Neonates with one of the following features (birth weight less than $1.7 \mathrm{~kg}$, APGAR score less than 7, gestational age less than 33 weeks and/or parenteral antibiotic treatment, nasal CPAP (Continuous supportive airway pressure), any intubation during the first week of life, phototherapy within 24 hours of birth, cardiopulmonary resuscitation, vasoactive drug use, anticonvulsants use, surfactant use, blood product use, steroid use, surgery during the first week of birth). ${ }^{5}$

Pragmatic criteria: defined as the combination of variables including (birth weight less than $1.7 \mathrm{~kg}$, APGAR score less than 7, gestational age less than 33 weeks. ${ }^{5}$

Management criteria: Defined as the use of parenteral antibiotic treatment, nasal CPAP (Continuous supportive airway pressure), any intubation during the first week of life, phototherapy within 24 hours of birth, cardiopulmonary resuscitation, vasoactive drug use, anticonvulsants use, surfactant use, blood product use, steroid use, surgery during the first week of birth). ${ }^{35}$

Knowledge of participants about neonatal danger signs: was measured using 'yes', "no" questions, participants were asked "did you know fever as neonatal danger sign"; participants who respond "yes" will score 1 and "no" response will earn zero scores. The same pattern of questioning and scoring was made for the rest of the nine neonatal danger signs questions. According to the aforementioned statements, the knowledge score for each participant could range from 0 to 10 . A total score of 3-10 was considered as "as having good knowledge" and scores of $0-2$ are labeled as having poor knowledge. ${ }^{35}$

Knowledge of participants about essential newborn care: was measured by using asking questions for participants about, "when the newborn should have the first bath"; participants who respond "the correct answer" will score 1, and "the incorrect answer" response will earn zero scores. The same pattern of questioning and scoring was made for the rest of the knowledge-related questions. Accordingly, participants who were responded to greater than $50 \%$ of knowledge-related questions correctly were considered as having good knowledge whereas participants who responded less than or equal to $50 \%$ of knowledge-related questions were considered as having poor knowledge. ${ }^{35}$

Essential newborn care practice: was measured by using asking questions for participants about "what kind of instruments used to cut the cord"; participants who respond "the correct answer" will score 1 and "the incorrect answer" response will earn zero scores. A similar pattern of questioning and scoring was made for the rest of the five practice-related questions. Accordingly, participants who have responded to all the six items as " 1 " or having cumulative essential newborn care practice, a score of 6/6 were labeled as having good ENC practice or else poor ENC practice. ${ }^{35}$

Severe maternal morbidity: mothers who were faced with one of the following cases including severe preeclampsia, severe anemia (hgb $<6 \mathrm{gm} / \mathrm{dl})$, sepsis, eclampsia, severe hemorrhage, obstetric diagnosis, dystocia. ${ }^{14}$

\section{Data Quality Measures}

Data collectors and supervisors underwent two days of intensive training on data collection methods, including the template for data abstraction, the research purpose, and data collection techniques. Besides, regular reviews were also carried out by the principal investigator and supervisors for the accuracy, consistency, and completeness of data obtained, and necessary adjustments were made on the spot.

\section{Data Processing and Analysis}

Using Epi Info7, the data were entered and exported to SPSS version 24 for analysis. Significant variables for the outcome variable were clarified by descriptive statistics such as frequencies, proportions, median, and mean. To analogize the proportion of cases and controls in terms of chosen categorical variables, the chi-square test was used. To test the equality of means for selected continuous variables between cases and controls, an independent sample $t$-test was also given. To evaluate the correlation of each independent variable with the outcome variable, binary logistic regression was performed. Then, multivariable logistic regression analysis was performed to manage confounding variables by simultaneously taking all variables with p-value $<0.2$ on binary logistic regression into the model. To announce that 
a variable is an independent determinant of the outcome variable, a P-value of 0.05 or less than and a modified odds ratio (AOR) with $95 \%$ confidence interval were used. To determine whether the model was correctly specified or the data ambivalent with assumptions were made by the model, Hosmer-Lemeshow's test was found to be insignificant ( $\mathrm{p}$-value $=0.73$ ) and Omnibus tests were significant (P-value $\leq 0.001)$ which indicate the model was fitted.

\section{Results}

Three hundred fourteen mothers with neonates (105 cases and 209 controls) were successfully interviewed, giving a $100 \%$ response rate.

\section{Socio-Demographic Attributes of Participants}

The mean age of cases was 28.7 years with a standard deviation of 4.6, while the mean age of controls was 27 with a standard deviation of 4.9 years. As shown by the independent sample $t$-test ( $\mathrm{P}$-value $=0.053$ ), the mean age difference between cases and controls is not statistically significant. Approximately, $56.5 \%$ of the control infants were males and $55.2 \%$ of the case infants were males. A majority (72.4\%) of cases were admitted with a referral letter from other health facilities concerning the mode of admission, while only $19.6 \%$ of controls were referred from other health facilities (Table 1).

\section{Reproductive History of Respondents}

The median number of pregnancies is 3 among mothers of cases with a minimum of 1 and a maximum of 8 numbers of pregnancies. The median number of live birth among mothers of cases is 2 live births. About $6.7 \%$ of mothers of cases have a history of stillbirth and $2.4 \%$ of mothers of controls have a history of stillbirth but the difference is not statistically significant among cases and controls (chi-square test- $p$-value $=0.064)$. Nineteen $(18.1 \%)$ of mothers of cases have a history of abortion while $6.1 \%$ of mothers of controls have a history of abortion. The chi-square test has revealed the difference is statistically significant at $(P$-value $=0.001)$ for this finding.

Almost two-third, $68.9 \%$ of mothers among controls have antenatal care visits for their last pregnancy, while $31.1 \%$ of mothers among cases have a history of antenatal care visits. With the chi-square test, the disparity between cases and controls in an antenatal visit is statistically significant (P-value $=0.01$ ). Around $20 \%$ of cases have a history of severe morbidity during pregnancy and $6.7 \%$ of the controls have severe morbidity during pregnancy. The observed difference between cases and controls in the morbidity of mothers is statistically significant at the chi-square test $(P$-value $=0.001)$.

Ten $(9.5 \%)$ mothers of cases had provided birth to the index child at home and 5(2.9\%) mothers of controls had provided the index child at home. The difference between controls and cases in place of birth is statistically significant (Chi-square test, $p$-value $=0.014$ ).

Table I Socio-Demographic Characteristics of Respondents in Gurage Zone Hospitals, 2020

\begin{tabular}{|c|c|c|c|c|c|}
\hline \multirow[t]{2}{*}{ Variable } & \multirow[t]{2}{*}{ Category } & \multicolumn{2}{|l|}{ Cases } & \multicolumn{2}{|l|}{ Controls } \\
\hline & & Frequency & Percentage & Frequency & Percentage \\
\hline \multirow[t]{2}{*}{ Residence } & Rural & 58 & 55.2 & 108 & 51.7 \\
\hline & Urban & 47 & 44.8 & 101 & 48.3 \\
\hline \multirow[t]{4}{*}{ Education status of women } & Illiterate & 39 & 37.1 & 44 & 21.1 \\
\hline & Primary school completed & 37 & 35.2 & 86 & $4 I . I$ \\
\hline & Secondary school & 17 & 16.2 & 52 & 24.9 \\
\hline & Diploma and above & 12 & 11.4 & 27 & 12.9 \\
\hline \multirow[t]{5}{*}{ Occupation of mothers } & Housewife & 75 & 71.4 & 135 & 64 \\
\hline & Government employee & 12 & $1 \mathrm{I} .4$ & 35 & 16.7 \\
\hline & Merchant & 8 & 7.6 & 33 & 15.8 \\
\hline & Daily laborer & 8 & 7.6 & 3 & 1.4 \\
\hline & Farmer & 2 & 1.9 & 3 & 1.4 \\
\hline
\end{tabular}




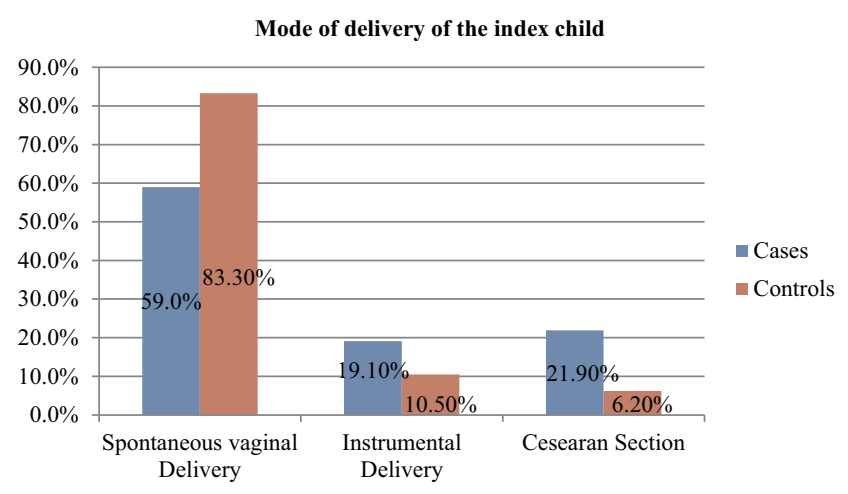

Figure I Mode of delivery of the index child among mothers of cases and controls in the Gurage zone, Ethiopia, 2020.

Approximately $61.2 \%$ of controls have an immediate postnatal visit at a health facility but only $29.5 \%$ of cases have a postnatal visit in the health facility. The observed disparity between controls and cases in the use of postnatal care visits is statistically significant (Chi-square test $P$-value $=0.0001)($ Figure 1$)$.

\section{Knowledge of Participants' About Essential Newborn Care}

Approximately $26.1 \%$ of controls believed that breastfeeding should be initiated immediately after birth, while $12.7 \%$ of cases believed that breastfeeding should be started immediately after birth. In the chi-square test ( $p$-value $<0.0001$ ), the observed difference in the timing of breastfeeding initiation among cases and controls is statistically significant (Figure 2).

About $27.7 \%$ of controls and $14.7 \%$ of cases know that the first neonatal bath should be postponed for 24 hours. In the chi-square test $(p=0.001)$, the observed difference between controls and cases in the information of the first bath is statistically significant.

\section{Knowledge of Participants About Neonatal Danger Signs}

It is considered that mothers who mentioned three and above neonatal danger signs are to have good knowledge of neonatal danger signs. Therefore, about $21.3 \%$ of controls have good knowledge of neonatal danger signs, while only $4.8 \%$ of cases have good knowledge of neonatal danger signs. In the chi-square test, the observed difference between cases and controls in the knowledge of neonatal danger sign is statistically significant at $(\mathrm{P}$ value $<0.001$ ) (Figure 3).

\section{Essential Newborn Care Practice of Participants}

Almost all mothers of controls and mothers of cases have a poor practice of essential newborn care. The proportion of essential newborn care practice is $4.1 \%$ and $1.6 \%$ for controls and cases respectively.

The majorities, $(58 \%)$ of mothers of controls have fed colostrum to their newborn but only $13.7 \%$ of mothers of cases have fed colostrum to their newborn. Colostrum feeding practice is significantly different among mothers and cases on the chi-square test $(P$ - value $<0.0001)$. Mothers of cases and controls who fed their infant food items other than breast milk are $2.9 \%$ and $5.4 \%$ respectively. The difference in introducing food items in the first week of life other than breast milk is not significant (chisquare test, $P$ value $=0.46$ ).



Figure 2 Knowledge of participants about the time of initiation of breastfeeding in Gurage zone hospitals, 2020. 


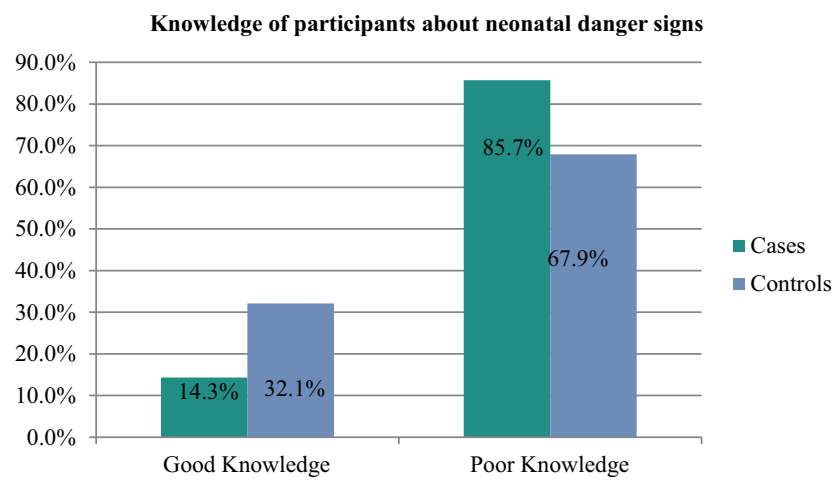

Figure 3 Knowledge of participants about neonatal danger signs in Gurage zone hospitals, 2020.

\section{Determinate Factors of Neonatal Near Miss Among Neonates}

To determine independent predictors of a neonatal near miss, bi-variable and multivariable logistic regression analysis was carried out. Multivariable logistic regression was performed for variables with a $p$-value $\leq 0.25$ on bivariable logistic regression. Accordingly, variables including the history of abortion, mode of admission, history of stillbirth, history of antenatal care, severe morbidity during pregnancy, place of birth, mode of delivery, postnatal care, essential newborn care knowledge have a $p \leq 0.25$ on bivariable logistic regression; thereby further analyzed on multi-variable logistic regression.

Independent predictors of the outcome variable include the history of abortion with AOR 3.9[95\%C1 3.53-10.15], a referral from other health care institution AOR 7.53[95\% CI 3.99-14.22], severe maternal morbidity during pregnancy AOR 4.57[95\% CI1.77-11.79], cesarean section mode of delivery $4.45[95 \%$ CI $1.76-11.25]$, and knowledge on essential newborn care 3.33[95\% CI1.54-7.19].

Neonatal near-miss cases are nearly four times more likely to develop among mothers who had a previous history of abortion as compared to mothers with no previous history of abortion. Neonates whose mothers are referred from other health care institution are seven times more likely to develop neonatal near miss conditions compared to the counterpart.

Severe maternal morbidity is also one of the predictors of a neonatal near-miss at which neonates whose mothers have a history of severe morbidity during pregnancy were four to five times more likely to develop neonatal near miss compared to the counterpart. Cesarean section mode of delivery increases the risk of a neonatal near miss by four to five times compared to mothers who had given birth by spontaneous vaginal delivery. Maternal knowledge of essential newborn care is also a decisive factor for neonatal health. Neonates whose mothers have poor knowledge of essential newborn care are three times more likely to develop neonatal near miss compared to the counterpart (Table 2).

\section{Discussion}

This study identified that prior history of abortion, mode of admission, severe morbidity during pregnancy, mode of delivery, and essential newborn care knowledge are independent determinate factors of a neonatal near miss.

In this finding, the cesarean section mode of delivery has shown an increased risk of neonatal near miss compared to spontaneous vaginal delivery. Mothers who give birth via cesarean section are four to five times more likely to have neonates with the near-miss condition compared to mothers who had given spontaneous vaginal delivery. The same findings are reported in Brazil and Arbaminch Ethiopia. ${ }^{22,23,36}$ This could be due to two main reasons; the first one is medical conditions that forced mothers to give birth via cesarean section could have a direct effect on the fetus. The second reason could be, surgical wound and anesthesia effect would limit mothers to care for the newborn which in turn leads to neonatal near miss happens. This finding implies that reducing the cesarean section mode of delivery could be one of the preventive strategies for the occurrences of a neonatal near miss.

Mothers who had had a history of severe maternal morbidity are four to five times more likely to develop neonatal near miss conditions compared to mothers with no severe morbidity during pregnancy. This report is in line with a study done elsewhere in Ethiopia. ${ }^{37}$ The reason is due to the direct effect of maternal morbidity on the unborn fetus and maternal inability to provide appropriate care for the newborn due to maternal medical conditions.

A finding reported in Brazil and Ethiopia also indicated that severe maternal morbidity (SAMM) increases the incidence of neonatal near- miss. ${ }^{38,39}$ Another finding conducted in low-income countries on a global view of severe maternal morbidity also found that: in addition to maternal mortality, severe maternal morbidity not only affects the woman's life at risk, but her fetus/neonate may also experience neonatal near-miss morbidity. ${ }^{39}$ This research work revealed that downscaling severe maternal morbidities (severe preeclampsia, severe anemia $(\mathrm{hgb}<6 \mathrm{gm} / \mathrm{dl})$, sepsis, eclampsia, severe hemorrhage, obstetric diagnosis, dystocia) are a preventive measure for the happening of neonatal near miss. 
Table 2 Predictors of Neonatal Near Miss Among Neonates Received Care in Gurage Zone Public Hospitals, Ethiopia, 2020

\begin{tabular}{|c|c|c|c|c|c|c|}
\hline Variable & Category & Cases & Controls & COR, $95 \% \mathrm{CI}$ & AOR, $95 \% \mathrm{Cl}$ & P-value \\
\hline \multirow[t]{2}{*}{ History of abortion } & Yes & 19 & 13 & $3.33(1.54-7.04)$ & $3.95(1.53-10.15)$ & 0.004 \\
\hline & No & 86 & 196 & I & I & \\
\hline \multirow[t]{2}{*}{ Mode of admission } & Self-referred & 28 & 145 & I & 1 & \\
\hline & Referred by facility & 77 & 64 & $6.23(3.69-|0.5|)$ & $7.53(3.99-14.22)$ & 0.0001 \\
\hline \multirow[t]{2}{*}{ History of stillbirth } & Yes & 7 & 5 & $2.9(0.90-9.41)$ & $2.73(0.44-16.75)$ & 0.27 \\
\hline & No & 98 & 204 & I & I & \\
\hline \multirow[t]{2}{*}{ History of ANC for the index child } & Yes & 87 & 193 & I & I & \\
\hline & No & 18 & 16 & $2.49(1.21-5.12)$ & $1.48(0.54-4.04)$ & 0.44 \\
\hline \multirow[t]{2}{*}{ Severe morbidity during pregnancy } & Yes & 21 & 14 & $3.48(1.69-7.17)$ & $4.57(1.77-11.79)$ & 0.002 \\
\hline & No & 84 & 195 & $\mathrm{I}$ & I & \\
\hline \multirow[t]{2}{*}{ Place of delivery } & Home & 10 & 6 & $3.56(1.25-10.08)$ & $3.88(0.40-36.91)$ & 0.23 \\
\hline & Health facility & 95 & 203 & I & & \\
\hline \multirow[t]{3}{*}{ Mode of delivery } & Spontaneous vaginal delivery & 62 & 174 & I & I & \\
\hline & Instrumental & 20 & 22 & $2.55(1.30-4.99)$ & $1.6 I(0.66-3.93)$ & 0.29 \\
\hline & Cesarean section & 23 & 13 & $4.96(2.37-10.40)$ & $4.45(1.76-11.25)$ & 0.002 \\
\hline \multirow[t]{2}{*}{ Postnatal care } & Yes & 31 & 128 & I & I & \\
\hline & No & 74 & 81 & $3.77(1.93-11.8)$ & $2.42(0.84-7.13)$ & 0.31 \\
\hline \multirow{2}{*}{$\begin{array}{l}\text { Knowledge of essential newborn } \\
\text { care }\end{array}$} & Poor knowledge & 90 & 142 & $2.83(1.24-5.25)$ & $3.33(1.54-7.19)$ & 0.002 \\
\hline & Good knowledge & 15 & 67 & I & I & \\
\hline
\end{tabular}

Neonatal near miss has been significantly correlated with essential newborn care knowledge. Compared to mothers who have good knowledge about essential newborn care, mothers who have poor knowledge of essential newborn care are three times more likely to have neonates with nearmiss clinical conditions. This is because mothers who have poor essential newborn care knowledge are less likely to practice essential newborn care that prevents neonatal disease and complications. This result is consistent with WHO and Ethiopian studies. ${ }^{5,37}$ This report alludes that provision of good and or sufficient perinatal counseling in the $\mathrm{MCH}$ clinic will help to mitigate the problem of severe neonatal morbidities or neonatal near misses.

Neonates admitted with referral paper from other health facilities are seven times more likely to develop neonatal near misses compared to self-referred motherneonate. This could be a result of delay to reach referral site and/or referred infants are more likely to have a more severe clinical condition than self-referred mother- neonate pair. This result is in line with a survey carried out in Uganda and Northeast Brazil. ${ }^{16,38}$ This study infers that increasing the access and availability of health services will help to decrease the episode of a neonatal nearmiss.

Neonates delivered from mothers with a history of abortion are three to four times more likely to develop neonatal near miss conditions compared to neonates delivered from mothers with no history of abortion. This result is in line with a study conducted elsewhere in Southeast Brazil and Benin, Burkina Faso, and Morocco. ${ }^{6,23}$ The possible justification could be a neonate born from women who had previously abortions could expose to urine scar, infection, bleeding, and injury on nearby reproductive organs which in turn causes abnormal birth weight, preterm birth and, complications during pregnancy and delivery. This in turn led to a neonatal near-miss. This result finding suggests that decreasing the incidence of abortion in women will help to lessen neonatal near-miss. 
The main importance of this study for any organization work in maternal and neonatal health are: identifying the determinate factors of neonatal near-miss is very important to mitigate the underlining risk factors and to provide immediate intervention. The finding of this study is also motivated different concerned bodies in the health care program to layout suitable techniques and objectives for the intervention to be done to avoid those significant determinate factors, both in the health care organization as well as in the society at large. This study becomes one tool for health policy planners for focusing on neonatal health in the health system.

This study is not without limitations, it would have produced more robust findings if prospective follow-up of pregnant women until the end of the neonatal period after birth. This would help to collect reliable maternal, health care, and neonatal characteristics that could determine neonatal near misses. Some of the data regarding maternal health and received services are retrospective hence recall bias cannot be fully ruled out.

\section{Conclusions}

In this study, easily modifiable/preventable maternal and health service utilization-related factors including the previous history of abortion, mode of admission, mode of delivery, severe maternal morbidity during pregnancy, maternal knowledge on essential newborn care are factors that independently predict neonatal near-miss in the Gurage zone. Therefore, amplifying maternal and child health care service in the study area for providing health information and counseling about essential newborn care and appropriate risk assessment during perinatal period focusing on prior history of abortion, mode of admission, severe morbidity during pregnancy, mode of delivery are recommended. Besides, since maternal and neonatal health is inextricably related the zonal health bureau shall emphasize improving neonatal health. Hence, comprehensive reproductive health services including preventing severe maternal morbidity and abortion are pivotal for having a healthy baby in subsequent births.

\section{Abbreviations}

ANC, Antenatal Care; MCH, Maternal and Child Health; NNM, Neonatal Near Miss.

\section{Data Sharing Statement}

On reasonable requests, the full data set and other materials related to this study can be obtained from the corresponding author.

\section{Ethical Approval and Consent to Participate}

The study protocol was accepted by the Wolkite University College of Medicine and Health Science research ethical review board and Ethical clearance was obtained. Permission letters were obtained from the Gurage Zone health office and the respective hospitals. After giving clear and relevant information about the aim of the study, informed consent was obtained from each respondent before the interview was conducted. Also, those women who can read and understand the Amharic language were given one page written overview of the study material. All qualifying mothers with neonates were voluntarily included in the research. Moreover, this study was conducted in compliance with the Declaration of Helsinki. Unwilling mothers were exempted from the study. Anonymous data were taken and the confidentiality of participant's information was secured.

\section{Acknowledgment}

We would like to acknowledge the acceptance of the research project by Wolkite University College of medicine and health science. Besides, our special gratitude goes to data collectors for their sincere effort to provide accurate information. Finally, we would like to wholeheartedly acknowledge study subjects without them this work could not be secured.

\section{Author Contributions}

All authors made substantial contributions to conception and design, acquisition of data, or analysis and interpretation of data; took part in drafting the article or revising it critically for important intellectual content; agreed to submit to the current journal; gave final approval of the version to be published; and agree to be accountable for all aspects of the work.

\section{Funding}

Wolkite University is funding this research. In the design of the research, data collection, examination, interpretation, writing the manuscript, and the decision to publish, the funder has no role.

\section{Disclosure}

There is no competing interests declared by the authors. 


\section{References}

1. Ezbakhe F, Pérez-foguet A. Child mortality levels and trends. Demographic Res. 2020;43:1263-1296. doi:10.1007/s00270-02002514-5

2. World Health Organization. Survive and thrive: transforming care for every small and sick newborn. Key findings. 2018. Available from: https://www.who.int/maternal_child_adolescent/documents/caresmall-sick-newborns-survive-thrive/en/.

3. Every woman every child: the global strategy for women's, children's, and adolescents' health (2016-2030). 2015. Available from: http://www.who.int/pmnch/media/events/2015/gs_2016_30.pdf. Accessed March 11, 2021.

4. UNICEF, World Health Organization. Every newborn progress report 2018 executive summary - healthy newborn network. Available from: https://www.healthynewbornnetwork.org/resource/every-new born-progress-report-2018-executive-summary/.

5. Pileggi-Castro CCJJ, Camelo jr JS, Perdoná GC, et al. Development of criteria for identifying neonatal near-miss cases: analysis of two WHO multicountry cross-sectional studies. Br J Obstet Gynecol. 2014;121:110-118. doi:10.1111/1471-0528.12637

6. Ronsmans C, Cresswell JA, Goufodji S, et al. Characteristics of a neonatal near-miss in hospitals in Benin, Burkina Faso, and Morocco in 2012-2013. Trop Med Int Health. 2016;2:535-545. doi:10.1111/tmi.12682

7. Avenant T. Neonatal near miss: a measure of the quality of obstetric care. Best Pract Res Clin Obstet Gynaecol. 2009;23:369-374.

8. Lawn JE, Blencowe H, Oza S, et al. Every newborn: progress, priorities, and potential beyond survival. The Lancet. 2014;384 (9938):189-205. doi:10.1016/S0140-6736(14)60496-7

9. UNICEF \& WHO. Low birthweight estimates. World Heal Organ. 2019;4(3):3-9.

10. Moss W, Darmstadt GL, Marsh DR, Black,RE, Santosham M. Research priorities for the reduction of perinatal and neonatal morbidity and mortality in developing country communities. J Perinatol. 2002;22(6):484-495. doi:10.1038/sj.jp.7210743

11. Helgertz JVD, Vågerö D. Small for gestational age and adulthood risk of disability pension: the contribution of childhood and adulthood conditions. Soc Sci Med. 2014;119:249-257. doi:10.1016/j. socscimed.2013.11.052

12. Uleanya ND, Aniwada EC, Ekwochi U, Uleanya ND. Short-term outcome and predictors of survival among birth asphyxiated babies at a tertiary academic hospital in Enugu, South East, Nigeria. Afri Heal Sci. 2019;19(1):1554-1562. doi:10.4314/ahs.v19i1.29

13. Santos JP, Cecatti JG, Serruya SJ, et al. Neonatal Near Miss: the need for a standard definition and appropriate criteria and the rationale for a prospective surveillance system. Clinics. 2015;70(12):820-826. doi:10.6061/clinics/2015(12)10

14. Anggondowati T, Aae E-M, Qomariyah SN, et al. Maternal characteristics and obstetrical complications impact neonatal outcomes in Indonesia: a prospective study. BMC Pregnancy Childbirth. 2017;17:100. doi:10.1186/s12884-017-1280-1

15. Survival(ALCS) AlfC: Africa key facts and figures for child mortality. 2012.

16. Nakimuli A, Mbalinda SN, Nabirye RC, et al. Stillbirths, neonatal deaths and neonatal near-miss cases attributable to severe obstetric complications: a prospective cohort study in two referral hospitals in Uganda. BMC Pediatr. 2015;15:44. doi:10.1186/s12887-015-0362-3

17. Grady SC, Franke AN, Zhang Q, et al. Neonatal mortality in East Africa and West Africa: a geographic analysis of district-level demographic and health survey data. Geospat Health. 2017;12(1):501. doi:10.4081/gh.2017.501

18. Mengesha HG, Sahle BW. Cause of neonatal deaths in Northern Ethiopia: a prospective cohort study. BMC Public Health. 2017;17 (1):62. doi:10.1186/s12889-016-3979-8
19. Ninama NH, Shroff BD. Will outlining neonatal near-miss events make a change? A hospital-based case-control study. J Community Med Public Heal. 2019;6(10):4570-4574. doi:10.18203/2394-6040. ijcmph20194520

20. Elisabeth M, Moreira L, Gurgel R, Sergipe UFD. Neonatal near miss in the Birth in Brazil survey neonatal near miss in the birth in Brazil survey Morbidade neonatal near miss na pesquisa Nascer no Brasil Nacer en Brasil. 2014

21. Surve S, Chauhan S, Kulkarni R. Neonatal near-miss review: tracking its conceptual evolution and way forward. Curr Pediatr Res. 2017;21:264-271.

22. de Lima TH, Katz L, Kassar SB, Amorim MM. Neonatal near miss determinants at a maternity hospital for high-risk pregnancy in Northeastern Brazil: a prospective study. BMC Pregnancy Childbirth. 2018;18(1):1-8. doi:10.1186/s12884-018-2020-x

23. Kale PL, Mhp M-J, Silva KSD, Fonseca SC. Neonatal near miss and mortality: factors associated with life-threatening conditions in newborns at six public maternity hospitals in Southeast Brazil. Cad Saude Publica. 2017;33(4):e00179115. doi:10.1590/0102-311x00179115

24. Morais LR, Patz BC, Campanharo FF, Dualib PM, Sun SY, Mattar R. Neonatal near miss among newborns of women with type 1 diabetes mellitus. Obstet Gynecol Int. 2019;2019:8594158. doi:10.1155/2019/ 8594158

25. Santos JP, Pileggi-Castro C, Camelo JS, et al. Neonatal near miss: a systematic review. BMC Pregnancy Childbirth. 2015;15:320. doi:10.1186/s12884-015-0758-y

26. Musooko MKO, Kakaire O, Nakimuli A, et al. Incidence and risk factors for early neonatal mortality in newborns with severe perinatal morbidity in Uganda. Int J Gynaecol Obstet. 2014;127(2):201-205. doi:10.1016/j.ijgo.2014.05.017

27. UN inter-agency group for child mortality estimation: levels and trends in child mortality. 2015. Available from: https://www.who. int/maternal_child_adolescent/documents/levels_trends_child_mortal ity_2015/en/.

28. Central statistical agency: Ethiopian demographic and health survey report. 2016. Available from: https://www.researchgate.net/publica tion/320109833_Ethiopian_Demographic_and_Health_Survey_2016.

29. Central statistical agency: Ethiopian demographic and health survey report. 2011. Available from: https://dhsprogram.com/pubs/pdf/PR10/ PR10.pdf.

30. CSA. CSA: mini demographic and health survey. 2019. Available from: https://dhsprogram.com/pubs/pdf/PR120/PR120.pdf.

31. United nation: sustainable development goals. 2016. Available from: https://unstats.un.org/sdgs/report/2016/.

32. Liu L, Oza S, Hogan D, et al. Global, regional, and national causes of child mortality in 2013, with projections to inform post-2015 priorities: an updated systematic analysis. The Lancet. 2015;385:430-440. doi:10.1016/S0140-6736(14)61698-6

33. United Nations(UN): transforming our world: the 2030 agenda for sustainable development. 2015. Available from: https://sustainablede velopment.un.org/post2015/transformingourworld/publication.

34. Central statistical agency: population and household census of Ethiopia. 2007. Available from: https://microdata.worldbank.org/ index.php/catalog/2747.

35. Young Infants Clinical Signs Study Group. Clinical signs that predict severe illness in children under age 2 months: a multi-center study. Lancet. 2008;371(9607):135-142. doi:10.1016/S0140-6736(08) 60106-3

36. Mersha A, Bante A, Shibiru S. Factors associated with neonatal near-miss in selected hospitals of Gamo and Gofa zones, southern Ethiopia: a nested case-control study. BMC Pregnancy Childbirth. 2019;19(1):516. doi:10.1186/s12884-019-2684-x

37. Tekelab T, Chojenta C, Smith R, Loxton D. Incidence and determinants of a neonatal near-miss in south Ethiopia: a prospective cohort study. BMC Pregnancy Childbirth. 2020;20(1):354. doi:10.1186/ s12884-020-03049-w 
38. Galvão LP, Alvim-Pereira F, de Mendonça CM, et al. The prevalence of severe maternal morbidity and near miss and associated factors in Sergipe, Northeast Brazil. BMC Pregnancy Childbirth. 2014;14(25). doi:10.1186/1471-2393-14-25
39. Fenta SL, Nigussie AA, Bante SA, et al. obstetric-near-miss-innorthwest-Ethiopia-has-a-pregnant-woman-still-one-foot-in-thegrave. Clinics Mother Child Health. 2020;17(4):100353.

\section{Publish your work in this journal}

Pediatric Health, Medicine and Therapeutics is an international, peerreviewed, open access journal publishing original research, reports, editorials, reviews and commentaries. All aspects of health maintenance, preventative measures and disease treatment interventions are addressed within the journal. Practitioners from all disciplines are invited to submit their work as well as healthcare researchers and patient support groups. The manuscript management system is completely online and includes a very quick and fair peer-review system. Visit http://www.dovepress.com/testimonials.php to read real quotes from published authors. 